Cuad. invest. hist., Brocar n. 15 (1989) Págs. 45-61

\title{
LA POBLACION DE LOGROÑO EN LOS VECINDARIOS DE LOS SIGLOS XVIII Y XIX
}

\author{
J.J. Alonso Castroviejo
}

\begin{abstract}
RESUMEN
Las únicas fuentes que nos ha legado la época preestadistica para conocer con exactitud su población son los recuentos de habitantes conocidos como padrones, vecindarios, censos o apeos. Las peculiaridades de su elaboración, la mayoría de las veces tenían un marcado carácter fiscal, hace que deban ser sometidos a un riguroso análisis para conocer su exactitud. El autor recoge en este articulo todos los censos de la ciudad de Logroño encontrados durante la investigación, los critica y por último intenta establecer la evolución demográfica de la ciudad entre los siglos XVIII y XIX.
\end{abstract}

The only sources of the pre-statistical age which could enable us to know its population exactly are the recounts known as padrones, vecindarios, censos, $o$ apeos. The peculiarities of their elaboration, (in most of cases they had a pronounced fiscal, purpose) oblige to analyze these recounts in a very rigorous way in order to discover their exactitude. In this paper, the author collects all the censos of the town of Logroño found during the process o research, criticizes them and finally tries to establish the demographic evolution of the city between the XVIIIth and XIXth centuries.

\section{RECUENTOS OFICIALES DEL SIGLO XVIII.}

La totalidad de los recuentos de población que se realizaron en la segunda mitad del siglo XVIII tienen un carácter fiscal, y de ahí que las cifras que nos ofrecen deban ser sometidas a un riguroso análisis para establecer su exactitud, o por el contrario su falsedad. Los censos generales, que intentaban contabilizar la población de todo el país, han sido frecuentemente utilizados por los investigadores y sometidos, desde sus respecti- 


\section{J.J. ALONSO CASTROVIEJO}

vas ópticas, a críticas en profundidad que permiten conocer su grado de validez ${ }^{1}$. De estas críticas se desprende que los vecindarios con mayores garantías son: para Castilla el recuento de vecinos incluido en las respuestas generales al Catastro del Marqués de la Ensenada y con una mayor exactitud la contabilización de los individuos que se detallan en los libros de respuestas particulares; y para la totalidad del país, el censo de habitantes mandado ejecutar por Floridablanca en 17872. Los censos de Aranda (1768) y Godoy (1797) presentarían mayores inexactitudes y lagunas y su utilización se presenta siempre con reservas y justificaciones críticas. Por último el Vecindario de Campoflorido (1716-1718) ofrece unas cifras que a todos los investigadores le parecen inaceptables ${ }^{3}$.

A continuación voy a intentar fijar el grado de credibilidad de los distintos vecindarios encontrados para el casco urbano de Logroño y sus barrios anejos del Cortijo y Varea.

\section{I.A. VECINDARIO DE 1714}

Se ha utilizado un manuscrito que sirvió de base para el posterior Vecindario de Campoflorido y que se conserva en la Biblioteca Nacional ${ }^{4}$. En este recuento sólo se contabilizaron los vecinos útiles que podían pagar la contribución impuesta por Felipe V. José Luis Gómez Urdáñez ya apuntó la falta de rigor de los vecindarios realizados durante la Guerra de Sucesión y lo ejemplifica con esta cifras: en 1709 el Ayuntamiento reparte las cargas de guerra entre 1.039 vecinos útiles. En 1712 sólo son 911 los que pueden soportar el repartimiento. Un año después el Intendente de Burgos manejaba un estadillo con 975 vecinos $^{5}$. Por último el manuscrito antes citado ofrece 967,5 vecinos útiles para 1714. Como se ve, en seis años tenemos cuatro vecindarios distintos, lo que en principio invalida cualquier aceptación de la población of recida; por lo tanto sólo me voy a permitir una aproximación especulativa a la cifra intermedia de 973 vecinos.

Los porcentajes de ocultación ofrecidos por F. Bustelo para el conjunto español no son en absoluto aplicables al caso logroñés, pues nos daría una población superior a la que ofrece el catastro de Ensenada, realizado cuarenta años después. Por otra parte, con una población no muy superior a 1.000 vecinos, las ocultaciones u omisiones serían muy difíciles, suponiendo el máximo celo en los ejecutores del vecindario, por lo que me inclino hacia una disminución en el monto impositivo en vez de una ocultación de la personalidad del contribuyente. Los exentos -Clero, nobleza, clases pudientes que pudieron evadirse- no superarían el $15 \% \%^{6}$ mientras que los pobres de solemnidad, viudas y otras capas marginales podian suponer el $18 \%{ }^{7}$.

1. Un análisis global puede hallarse en F. BUSTELO, «La población española en la segunda mitad del siglo XVIII». Moneda y Crédito n. ${ }^{\circ} 123$. Madrid, 1972 o en P. ROMERO SOLIS, La población española en los siglos XVIII y XIX. Madrid, 1973.

2. Sobre la fiabilidad del Catastro, J. M. DONEZAR, Riqueza y propiedad en la Castilla del Antiguo Régimen. Madrid, 1984, pp. 78-79. Para la exactitud del Censo de Floridablanca, P. VILAR, Cataluña en la España moderna, pp. 31-40, vol II. Barcelona, 1987.

3. F. BUSTELO, «EI vecindario general de España de 1712-1717» en Revista Internacional de Sociologia. n. ${ }^{\circ}$ XXXII. 1973.

4. Biblioteca Nacional, Leg. H. 131.

5. J. L. GOMEZ URDAÑEZ, «Reacciones populares en Logroño durante la Guerra de Sucesión» en Actas del Segundo Coloquio sobre Historia de La Rioja. Logroño, 1986, vol. 2, p. 189.

6. Porcentajes de exentos -Clero y nobleza- según las respuestas particulares del Catastro de Ensenada. A.H.P. Logroño, sec. Catastro, Libros 334-338.

7. Extraído de los vecindarios y repartimientos de la segunda mitad del siglo XVIII. 
Entre ambos segmentos representan 1/3 de la teórica población total de la ciudad, que añadido a los 973 vecinos útiles, nos ofrece 1.294 vecinos que suponen 5.176 habitantes, utilizando un coeficiente de conversión $4^{8}$. Los resultados así obtenidos tienen la virtualidad de encajar tanto en la evolución posterior de la propia ciudad, como con otras zonas del país ${ }^{9}$, pero hay que recalcar que estas cifras se ofrecen con toda clase de reservas y a título exclusivamente orientativo.

\section{I.B. PADRON CASA-HITA. 1737}

La supresión de algunos servicios en 1724, para los cuales eran necesarios los padrones o vecindarios como documento fiscal de los repartos, había originado una situación de confusión y desinformación en los centros administrativos que una orden de la Chancillería de Valladolid, promulgada en 1736, intentaba remediar. En ella se reflejaba el malestar de los gobernantes por la situación y por la desidia de las justicias de los pueblos y lugares que no cumplían con sus obligaciones administrativas:

"Como por el descuido y poca aplicación de las justicias y concejos en hacer como debian para otros efectos los referidos conocimientos y padrones y en conservar $y$ guardar y poner la formalidad necesaria en los repartimientos y listas que se ejecutan» ${ }^{10}$

El valor demográfico de este tipo de recuentos de marcado carácter fiscal es casi nulo y la orden de su realización lo especifica con claridad:

«Formen lista, padrón calle-hita y vecindario general de todos los que en la ciudad, villa o lugar tuvieren actual vecindad [...] con el nombre sólo [...] y dando a cada uno con distinción y claridad el estado que corresponda [...] poniendo al pechero por pechero $y$ al hidalgo por hidalgo..." 11

Se excluía por lo tanto a las viudas y a aquellos que no habían formado familia, pues sólo se anotaba a los cabeza de casa. La única utilidad de este padrón reside en que se puede conocer la relación existente entre clases privilegiadas y estado general. El número de vecinos ofrecido es de 943, completamente inadmisible pues supondría un retroceso demográfico que ningún otro indicador confirma. Tampoco la evolución de la población española refleja un retroceso entre 1714 y 1751, por lo que este padrón no debe ser considerado a efectos demográficos.

8. He aplicado este coeficiente por ser el más cercano a la media que se halla utilizando los vecindarios de $1751,1770,1818$ y 1822 .

9. Similares porcentajes ofrece E. FERNANDEZ DE PINEDO, Crecimiento económico y transformaciones sociales en el Pais Vasco. 1150-1850. Madrid, 1974, p. 90.

10. A.R.Ch. Valladolid, sec. Protocolos, leg. 157 exp. 32.

11. Ibídem. 


\section{J.J. ALONSO CASTROVIEJO}

\section{I.C. CATASTRO DEL MARQUES DE ENSENADA. 1751}

El Catastro es uno de los corpus documentales más importantes que nos ha legado la Edad Moderna. Los investigadores que lo han utilizado no muestran las prevenciones críticas que se suelen emplear con otras fuentes y los datos que ofrece son aceptados casi con unanimidad como altamente fiables ${ }^{12}$. La información demográfica contenida en las respuestas generales y el desglose persona por persona recogido en las respuestas particulares no ofrecen ninguna duda sobre su exactitud y así van a ser utilizados en este trabajo.

Logroño contaba en 1751 con 1.614 vecinos y 6.136 habitantes, repartiéndose la población entre los 1.539 vecinos y 5.869 habitantes del casco urbano y los 75 vecinos que suponen 267 habitantes de sus barrios anejos ${ }^{13}$.

\section{I.D. CENSO DE ARANDA. 1768}

La fiabilidad del censo realizado en 1768 , ha sido puesta en entredicho por todos los investigadores que lo han utilizado. Mientras que unos piensan que es deficiente por defecto, otros, como Pierre Vilar, piensan que lo es por exceso ${ }^{14}$.

La cifra que ofrece para Logroño y sus barios es de 7.408 habitantes, población que está claramente sobrevalorada ${ }^{15}$. Aceptarla supone un crecimiento anual de un $1,1 \%$, porcentaje que sólo se alcanzó en algunas zonas de la periferia, cuyo crecimiento fue más espectacular que el del interior, espacio en el que se encuentra la ciudad en estudio. El resto de indicadores demográficos tampoco confirman la exactitud de las cifras ${ }^{16}$.

Aunque los resultados no puedan asumirse, si que este censo sirve para constatar un hecho ya reseñado por otros investigadores, como es el de fijar el máximo poblacional del siglo XVIII en torno al año $1770^{17}$ para, a partir de ese momento, iniciarse un estancamiento que sólo fue superado, al menos para Logroño, en los últimos años del siglo. Esta tendencia se refleja en el vecindario que estudio a continuación.

\section{I.E. VECINDARIO DE 1770}

El vecindario de 1770 formaba parte de una ambiciosa operación estadística que pretendía poner al día el viejo proyecto de la Unica Contribución. La metodología empleada para conocer la riqueza de la ciudad -en el ramo agrario, industrial y comer-

12. Los análisis críticos a los que ha sido sometido el Catastro pueden verse en GRUPO 75, $L a$ economía del Antiguo Régimen. La Renta Nacional de la Corona de Castilla. Madrid, 1977 y en J. M. DONEZAR, op. cit.

13. A.H.Pr.Lo., sec. Catastro, Libro 333.

14. P. VILAR, Cataluña... pp. 28-31.

15. R.A.H. Obispado de Calahorra. El pleito entre cosecheros de vino y un viticultor independiente pudo influir en que los regidores inflaran el Censo para resaltar la población que vivía de las labores de la vid y que en un supuesto fallo en su contra, tendría que emigrar o verse abocada a la pobreza.

16. Al no conocer la mortalidad infantil no se puede establecer con exactitud el saldo vegetativo. Sin embargo las cifras del vecindario de 1770 se adecúan mejor a la realidad demográfica de este período. Vid nota 31.

17. A. GARCIA SANZ, Desarrollo y crisis del Antiguo Régimen en Castilla la Vieja. Madrid, 1986 , pp. $39-40$. 
cial- fue similar a la utilizada en la confección del catastro de 1751 y sus resultados similares.

La encuesta demográfica se ejecutó a partir de interrogatorios individualizados en los que el cabeza de familia debía declarar el número de familiares a su cargo, hijos e hijas, si los tenía, oficio que desempeñaba y parroquia. En caso de haber algún miembro de la familia ausente, éste se apuntaba como tal y no se contabilizaba en el cómputo general. Los encuestadores apuntaron a las viudas y a las solteras cabeza de casa como medio vecino, siguiendo la práctica habitual, y no incluyeron al Clero regular pero sí a sus criados. La encuesta reflejaba también la edad de cada uno de los habitantes, pero su excesivo redondeo hace imposible confeccionar una pirámide de edades; respuestas como: «declaró tener cercanos a los 40 años», son demasiado frecuente se inutilizan el conjunto $^{18}$. Salvadas estas dos pequeñas irregularidades -edades y Clero regular- los resultados son plenamente asumibles. Logroño tenía en 1770 una población de 1.650 vecinos que equivalen a 6.452 habitantes y sus barrios del Cortijo y Varea 94 y 386 respectivamente, a los que hay que añadir 320 sacerdotes y monjas que componían la totalidad del Clero regular de los conventos de la ciudad ${ }^{19}$, con lo que las cifras definitivas son estas:

\section{CUADRO 1 \\ VECINDARIO DE 1770}

$\begin{array}{lrr} & \text { Vecinos } & \text { Habitantes } \\ \text { Logroño } & 1.650 & 6.772 \\ \text { El Cortijo y Varea } & 94 & 386 \\ \text { Total } & 1.744 & 7.158\end{array}$

Cifras más ponderadas que las anteriores y que fueron posibles gracias a un crecimiento basado en una coyuntura agraria favorable promovida por la orientación vinícola de su campo que requería abundante mano de obra jornalera, que cuando no la podía ofrecer el propio Logroño, era demandada a las zonas limítrofes, estableciéndose así un flujo migratorio positivo que coadyuvó decisivamente a la expansión demográfica de la ciudad.

\section{I.F. VECINDARIOS DE 1773, 1775 Y 1784}

Entre 1770 y 1797 se realizaron en Logroño numerosos recuentos de población de los que sólo se conservan completos tres de ellos, los de los años 1773, 1775 y 1787. De los años 1784 y 1797 se conservan los cuadernillos de algunos barrios ${ }^{20}$.

18. A.M.Lo. I.C.Exp. caja 334.

20. A.M.Lo. I.C.Exp. caja 333, piezas 3 a 7. 
El vecindario de 1773 se realizó para cumplir una real orden de la que nada se especifica «expresando quién vive, qué oficio, qué hijos varones, la edad hasta el día de cada uno, omitiendo las hembras y el que tuviere criados también se expresarán »²!

La finalidad de este nuevo recuento era de de servir la base a las listas de alistamientos que se estaban realizando en toda España. El resultado de la operación en Logroño fue una sucinta relación socio-profesional de los habitantes de la ciudad, sin ningún valor demográfico, pues a la omisión de las mujeres hay que añadir la del Clero regular y una infravaloración de los hijos varones, natural considerando la naturaleza militar del censo.

Las cifras $-1.474,5$ vecinos, que significan 5.898 habitantes- son inaceptables, pues suponen una disminución de 175,5 vecinos y 874 habitantes en tres años. Esta pérdida poblacional es imposible a pesar de las crisis de mortalidad infantil de los dos años anteriores, cuyo saldo negativo se reduce a 248 personas.

Ante la inexactitud de este censo, en 1775 se volvió a cursar orden para que se realizara un nuevo recuento de población, con similares instrucciones a las de $1773^{22}$. Por los resultados que nos ofrece tampoco este nuevo vecindario merece confianza, aunque la cifra de habitantes pueda acercarse a la realidad. Logroño contaba en 1775 con $1.591,5$ vecinos, que utilizando un coeficiente de conversión 4 suponen 6.366 personas para el casco urbano, pues de los barrios de El Cortijo y Varea no he encontrado los originales. Este vecindario no contabilizaba al Clero regular -320 personas entre monjes y monjasque unido al cómputo anterior nos ofrece unos resultados -6.686 habitantes- que se acercan a la población con que contaba Logroño en 1770. El movimiento natural es negativo en 78 personas lo que no explica el bajo número de vecinos del recuento de 1775 aunque sí el que los habitantes hayan disminuido casi en esa cantidad. Por otra parte, los flujos migratorios de estos cinco años no fueron tan negativos como para perder 59 vecinos en un momento coyuntural aún favorable para el cultivo de la vid y la posterior comercialización de su producto. En conclusión, creo que mientras el número de habitantes obtenido utilizando el coeficiente de conversión 4 puede ser verosímil, el cómputo de vecinos es erróneo, quizás por una contabilización que no contempló a la totalidad de los mismos, pues su fin no era estadístico sino militar.

De 1784 se conservan íntegros los estadillos de población de los barrios tercero, cuarto y quinto ${ }^{23}$. La metodología empleada para su confección es similar a la del vecindario de 1770 , del que ya conocemos su exactitud. Los resultados que ofrece se resumen en 762 vecinos y 2.884 habitantes. Para poder extrapolar estas cifras se han hallado los porcentajes de ocupación de cada uno de los barrios logroñeses según los vecindarios de $1773,1775,1787,1811,1818$ y $1836^{24}$. Los ocupantes de estos tres barrios

21. Ibídem, pieza 3.

22. Ibídem, pieza 4.

23 A.M.Lo. I.C.Exp. caja 333 pieza 5.

24. Los porcentajes son los siguientes:

$\begin{array}{lrrrrrrr} & \text { I } & \text { II } & \text { III } & \text { IV } & \text { V } & \text { VI } & \text { VII } \\ 1773 & 13 & 11 & 16 & 16 & 14 & 13 & 17 \\ 1775 & 12 & 9 & 17 & 14 & 15 & 15 & 18 \\ 1787 & 11 & 14 & 15 & 15 & 15 & 17 & 13 \\ 1811 & 13 & 8 & 16 & 16 & 16 & 13 & 18 \\ 1818 & 13 & 10 & 18 & 14 & 15 & 12 & 18 \\ 1836 & 18 & 12 & 16 & 12 & 11 & 12 & 18 \\ \text { PROMEDIO } & 13 & 11 & 16 & 14,5 & 14,5 & 14 & 17\end{array}$


suponían el $45 \%$ de la población del casco urbano, pues no se han tenido en cuenta los dos barrios anejos de los que se carece de información para este año. Una vez aplicado el porcentaje de ocupación a las cifras obtenidas la población de Logroño era de 6.409 habitantes a los que hay que añadir nuevamente el Clero regular -320 personas-. El resultado 6.729 personas, es muy similar al ofrecido por el censo de 1775 y vuelve a poner de manifiesto que la ciudad experimentó durante estos años un profundo estancamiento demográfico motivado por una continuada serie de sobremortalidades y un parón de los flujos inmigratorios que hasta entonces había acogido Logroño.

Creo que es necesario señalar que tanto el recuento de 1775 como el de 1784 no reúnen las suficientes garantías de exactitud como para que los resultados expuestos deban ser aceptados en sí mismos. Si los he incluido en este apartado es porque a pesar de sus deficiencias muestran una clara tendencia de estancamiento que se verá plenamente confirmada cuando se expongan las cifras que ofrece el Censo de Floridablanca para la ciudad de Logroño.

\section{I.G. CENSO DE FLORIDABLANCA. 1787}

Se ha considerado este censo como el más fiable de todos los realizados en el siglo $\mathrm{XVIII}^{25}$, sin embargo los resultados que ofrece para Logroño tienen que ser matizados ${ }^{26}$. En primer lugar, en el cómputo por edades no están incluidos ni el Clero regular ni el secular, cuyo estado aparece en un folio aparte. Las cifras obtenidas deben ser, por lo tanto, sumadas al total por edades. En segundo lugar no se han incluido los datos referentes a los barrios de El Cortijo y Varea, por lo que la población que obtenemos no puede ser comparada con el resto de los vecindarios sino sólo con las cifras que éstos ofrecen para el casco urbano ${ }^{27}$.

El Censo de 1787, una vez aclarados los errores en su realización, cifra la población de Logroño en 6.303 habitantes seglares, 119 pertenecientes al Clero secular y 368 al Clero regular, siendo el total de 6.790 habitantes. Este resultado que puede ser aceptado sin reservas, confirma plenamente la hipótesis del grave estancamiento demográfico que los anteriores recuentos ya apuntaban y que se debe a la conjunción de factores demográficos -crisis de mortalidad- con factores económicos, que impidieron que el crecimiento experimentado hasta 1770 continuara.

\section{I.H. CENSO DE GODOY. 1797}

Este censo ha sido criticado por todos los investigadores que lo han utilizado, basándose en que las cifras que ofrece están subestimadas cuando no repetidas del Censo de Floridablanca ${ }^{28}$. Para Logroño sólo dispongo del borrador del barrio séptimo y de los

25. P. VILAR, Cataluña... pp. 31-40, E. GIMENEZ LOPEZ, Alicante en siglo XVIII, Valencia 1981, p. 47; E FERNANDEZ DE PINEDO, op. cit. pp. 81-82.

26. A.M.Lo. I.C.Exp. caja 333, pieza 6. Las cifras del borrador han sido contrastadas con las definitivas que se encuentran en la R.A.H. y que me han sido facilitadas por Pedro Gurría.

27. Me baso en los porcentajes de ocupación por barrios que no presentan ninguna distorsión notable. Vid nota 24.

28. E. FERNANDEZ DE PINEDO, «Coyuntura y política económica» en la obra colectiva Centralismo, Ilustración y Agonía del Antiguo Régimen (1714-1833). Barcelona, 1980, p. 19. 
de las aldeas de El Cortijo y Varea ${ }^{29}$. Mientras que la cifra de habitantes que ofrece para el barrio séptimo es verosímil, 1.033 habitantes, no lo es la de vecinos, 353,5, demasiado elevada y que supone un coeficiente habitantes/vecinos de solamente 2,9 , inaceptable a todas luces, pues los coeficientes de otros vecindarios están todos en torno a 4 . Desconozco las causas que puedan justificar esta acusada disparidad. Las cifras de los dos barrios anejos sí pueden ser asumidas sin crítica, 430 habitantes.

Si aplicamos los porcentajes de ocupación por barrios a la cifra de habitantes del barrio séptimo obtenemos una población aproximada para la ciudad de 6.450 personas, a la que hay que añadir la población institucional, evaluada en unas 400 personas más ${ }^{30}$. Los 6.850 habitantes representan un mínimo incremento con respecto a la población de 1787 que no se corresponde con el crecimiento natural experimentado entre estos dos años; tampoco hay que suponer una emigración numerosa, pues las cifras obtenidas para el período 1787-1802 sólo ofrecen un saldo migratorio negativo de 103 personas $^{31}$.

El cálculo efectuado a partir de la información parcial encontrada no permite que se realice una crítica más rigurosa del censo y que sus resultados sean utilizados en este trabajo. El vecindario de 1802 nos permitirá conocer con mayor exactitud la población de Logroño en el cambio de siglo.

\section{I.1. CRECIMIENTO DEMOGRAFICO 1714-1787}

Las conclusiones que se pueden establecer después del estudio de los vecindarios aportados durante la investigación se concretan en la constatación de que las principales fases del crecimiento demográfico descritas en otras zonas del país pueden aplicarse también a Logroño ${ }^{32}$.

El crecimiento fue moderado entre 1714 y 1751 , a razón de un $0,46 \%$ anual, para incrementarse poderosamente entre esta última fecha y 1770 , en que se alcanzan las máximas cotas de población, creciendo, entre las dos fechas señaladas, a un ritmo anual de un $0,81 \%$, cifra posible gracias a una coyuntura agraria favorable que posibilitó una fuerte corriente inmigratoria. La orientación vinícola de la ciudad está en la base de este comportamiento y se sitúan en estos años las primeras roturaciones de importancia.

Este modelo de crecimiento apoyado en el factor repoblador del cultivo de la vid, llegó a su techo hacia 1770. A partir de este momento y hasta 1787 se sucedieron las crisis de mortalidad -dos en 17 años-, crisis agrarias y una superproducción vinícola que no encontro colocación en el colapsado mercado exterior y arruinó a los productores ${ }^{33}$. Esta desfavorable coyuntura económica frenó de una manera drástica el crecimiento demográfico urbano. Entre 1770 y 1787, Logroño creció a un ritmo anual de un 0,018\%

29. A.M.Lo. I.C.Exp. caja 333, pieza 7.

30. Según las cifras del Censo de Floridablanca.

31. ALONSO CASTROVIEJO, J.J., La crisis del Antiguo Régimen en Logroño. Propiedad, capital y transformaciones sociales. $1766+1833$, pp. 32-101, para un conocimiento más completo de las variables demográficas. Tesis doctoral inédita.

32. V. PEREZ MOREDA, «Evolución de la población española desde finales del Antiguo Régimen» en Papeles de Economía Española. Madrid, 1984, no. 20, pp. 20-38. R. FERNANDEZ «Introducción» pp. 34-35 en la obra colectiva España en el siglo XVIII. Barcelona, 1985.

33. En 1785 el vino se vendió a un real la cántara debido a la excesiva cosecha. 
que ejemplifica claramente el estancamiento que sufrió la ciudad. Tal como señala Angel García Sanz para algunas zonas de Segovia y E. Fernández de Pinedo para la Rioja alavesa, muy cercana a Logroño, la orientación vinícola de estas comarcas imposibilitó su crecimiento demográfico cuando las condiciones de los intercambios cereales-vino empezaron a ser desfavorables para este último ${ }^{34}$. La idea de una reconversión de los cultivos empieza a asentarse en Logroño en las dos últimas décadas del siglo XVIII.

\section{CUADRO 2}

\section{TASA DE CRECIMIENTO ANUAL ACUMULADO. 1714-1787}

\begin{tabular}{cccccc}
\multicolumn{2}{c}{ Tasa anual } & \multicolumn{2}{c}{ Tasa anual } & \multicolumn{2}{c}{ Tasa anual } \\
$1714-1751$ & $0,46 \%$ & $1714-1770$ & $0,58 \%$ & & \\
$1751-1770$ & $0,81 \%$ & $1751-1787$ & $0,43 \%$ & $1714-1787$ & $0,45 \%$ \\
$1770-1787$ & $0,018 \%^{*}$ & & & &
\end{tabular}

* Al faltar la población de los barrios anejos para el censo de 1787, ésta se ha estimado en 390 habitantes, siguiendo la evolución que muestran los demás vecindarios.

\section{LA POBLACION DE LOGROÑO EN EL SIGLO XIX.}

Desgraciadamente tanto la cantidad como la calidad de los recuentos de población de la primera mitad del siglo XIX no es la que el investigador desearía ${ }^{35}$. Logroño no es una excepción y en cincuenta años sólo puedo ofrecer siete recuentos, algunos de ellos sin demasiadas garantías de exactitud.

\section{II.A. PADRON DE 1802}

Este primer recuento se realizó bajo las mismas disposiciones legales de 1736, pero mientras que este padrón tenía un marcado carácter fiscal, que invalidaba sus resultados, el de 1802 se confeccionó para conocer con exactitud la estructura social logroñesa en un momento en el que era necesario fijar la filiación para poder optar a los cargos concejiles, que se habían convertido en anuales. Por ello las limitaciones demográficas de este padrón son obvias, pero más fácilmente subsanables que las que presentan otros recuentos. Los principales grupos sociales que no aparecen reflejados son las viudas y la población institucional -tanto Clero regular como grupos marginales acogidos en las casas de misericordia- que junto a una pequeñas ocultación, tanto técnica como provoca-

34. A. GARCIA SANZ, op. cit. pp. 68-70 y E. FERNANDEZ DE PINEDO, Crecimiento..., pp. 130-131.

35. E. FERNANDEZ DE PINEDO, Crecimiento..., p. 88. 
da, suponen un $17 \%$ de la población ${ }^{36}$. Los grupos con status social bajo pero que tenían habitación en la ciudad y trabajo, aun temporal, se incluyeron en el recuento, cuyos resultados se ofrecen en el siguiente cuadro:

\section{CUADRO 3 \\ POBLACION DE LOGROÑO EN 1802}

\begin{tabular}{lcccc} 
& Padrón & \multicolumn{3}{c}{$+17 \%$} \\
& Vecinos & Habitantes & Vecinos & Habitantes \\
Logroño & 1.530 & 6.120 & 1.790 & 7.160 \\
Barrios & 94 & 376 & 110 & 440 \\
& 1.624 & $\overline{6.496}$ & 1.900 & 7.600
\end{tabular}

Estos resultados responden perfectamente a lo que fue la evolución demográfica de la ciudad, pues los indicadores así lo demuestran: la tasa de natalidad es en 1802 de un 39,11 por mil, mientras que la de 1787 era inferior, un 38,58 por mil. También se observa un incremento en el número de nacimientos, pues mientras que en torno a 1787 el índice es de 108, en torno a 1802 este índice se ha elevado hasta 116 . El crecimiento natural entre 1787 y 1802 es de 473 personas. Este saldo vegetativo es superior a la población de 1802 , por lo que tenemos que suponer que la diferencia negativa de 103 personas es consecuencia de un proceso de emigración motivado por la reorientación de las estructuras productivas, cuyo exponente más claro fue la reducción de la superficie dedicada a la vid en zonas de regadío, para cultivar cereales en un momento en el que los factores de intercambio cereales-vid se habian decantado a favor del primero.

A pesar de esta pérdida de población motivada por la emigración, Logroño superó tímidamente el estancamiento demográfico de la fase anterior, pues si entre 1770-1787 su tasa de crecimiento anual fue solamente de un $0,018 \%$, entre 1787 y 1802 ésta se elevó hasta un $0,38 \%$, gracias al vigoroso crecimiento natural que se experimentó entre esas dos fechas, que fue el mayor de todo el período de estudio.

\section{II.B. VECINDARIO DE 1811}

Logroño estuvo ocupado durante toda la Guerra de la Independencia por las tropas francesas. La administración invasora se encargó de cobrar durante estos años todos los impuestos extraordinarios que sus tropas necesitaron ${ }^{37}$. De los vecindarios realizados para la cobranza se ha conservado íntegro el de 1811, que a pesar de tener una finalidad fiscal posee además un gran valor demográfico, pues refleja la totalidad de vecinos de la ciudad, ya que los que no podían pagar en metálico eran reclamados para obras de fortificación o acarreo de intendencia. Las viudas fueron igualmente inscritas, pues también ellas debían servir al ejército francés ${ }^{38}$.

36. A.R.Ch. Valladolid, sec. protocolos Leg. 173 exp. 3. Los porcentajes de ocultación han sido calculados a partir de la información suministrada por otros censos y es el siguiente: Viudas $6 \%$, pob. institucional 6\%, ocultación 5\%.

37. M. CARMEN SOBRON, Logroño durante la Guerra de la Independencia. Logroño, 1987.

38. A.M.Lo. I. L. A. $n^{\circ} .28$. 
El vecindario divide a los vecinos de la ciudad en tres categorias: los útiles, que podian pagar íntegramente en metálico las exacciones, los casi inútiles que debían realizar actividades de colaboración y por último los inútiles, que debido a su nula fortuna eran empleados como mano de obra barata. Esta división de los pobladores de la ciudad tenía la ventaja de que incluyó en la misma a todos los habitantes de Logroño mayores de edad susceptibles de realizar cualquier tipo de colaboración -ya fuera en metálico, ya en trabajo- con el ejército invasor. Por ello el resultado que nos ofrece puede ser asumido a efectos demográficos sin reticencias:

\section{CUADRO 4 VECINDARIO DE 1811}

Vecinos útiles Vecinos casi inútiles Vecinos inútiles
Habitantes

$\begin{array}{r}802 \\ 646 \\ 298 \\ \hline 1.746\end{array}$
y Varea.

* Se ha utilizado un coeficiente de conversión 4 y se incluyen los barrios anejos de El Cortijo

La pérdida de población es lógica si consideramos que entre esas dos fechas se produjo la crisis de mortalidad de los años 1803-1804 en la que murieron unos 800 habitantes en la ciudad, y que durante el verano de 1809 hubo una sobremortalidad infantil que no ha podido ser cuntificada con exactitud ${ }^{39}$. En resumen Logroño perdió entre 1802 y 1811, si aceptamos las cifras de ambos recuentos, un $8 \%$ de la población censada, cifra considerable y que refleja la gravedad de la crisis $^{40}$.

\section{II.C. APEO DE 1818}

Este vecindario forma parte de la encuesta que por mandato del Ministro de Hacienda, Martín de Garay, se realizó en toda España para conocer la riqueza nacional y establecer un nuevo sistema impositivo que aliviara la quiebra de la Hacienda Pública ${ }^{41}$.

La metodología utilizada es igual a la que se empleó para la elaboración del Censo de Floridablanca, distinguiendo entre varones y hembras, solteros, casados y viudos, distribuidos por grupos de edades e incluyendo al Clero secular. La única ausencia es la del barrio de Varea que no aparece en el original ${ }^{42}$ :

39. Los párrocos avisaron de la gravedad de la crisis, aunque no se pueda cuantificar debido a que no se anotaron todas las defunciones.

40. Esta crisis fue más importante en Logroño que en otras zonas de La Rioja.

41. J. FONTANA, La quiebra de la Monarquía Absoluta. 1814-1820. Barcelona, 1978, pp. 170-175.

42. A.M.Lo. I.C.Exp. caja $328 n^{\circ}$. 1. Se encuentra completo en A. C. Calahorra, caja 3.341, que aunque fechado en 1821 , repite las cifras de 1818. 


\section{CUADRO 5 APEO DE 1818}

$\begin{array}{lcc} & \text { Vecinos } & \text { Habitantes } \\ \text { Logroño } & 1.764 & 7.077 \\ \text { El Cortijo } & 94 & 358 \\ \text { Varea } & 30 & 109 \\ & 1.888 & \overline{7.544}\end{array}$

El retroceso demográfico experimentado en los primeros años del siglo XIX había sido superado gracias a un notable incremento de las tasas de natalidad y a una ralentización de la mortalidad ordinaria ${ }^{43}$, lo que permitió que durante unos años los saldos vegetativos fueran positivos. La reacción demográfica tras la guerra no fue exclusiva de Logroño, sino que se produjo también en otras zonas de La Rioja ${ }^{44}$, confiriendo a estos años un carácter de crecimiento demográíico generalizado, en el que influyó, al menos en La Rioja, la roturación y puesta en cultivo de importantes extensiones de tierra que hasta la guerra fueron propiedad del Común, dedicadas a pastos, y que se desamortizaron en favor de los capitalistas locales. En Logroño esta enajenación afectó a 954 fanegas de tierra de regadío ${ }^{45}$ que permitieron una mayor obtención de recursos en una etapa en la que el comercio interior estaba paralizado.

\section{II.D. PLAN DE DEMARCACION DE 1822}

Este recuento es el único de todos los estudiados que no tiene carácter fiscal, ya que se realizó por orden del Obispo de la diócesis D. Anastasio Puyal y Póveda para intentar corregir «el estado irregular de confusión y desorden en que se hallan las parroquias de dicha ciudad de Logroño por no tener demarcados y señalados los límites de su respectivo territorio» ${ }^{46}$. Para ello se comisionó a varios sacerdotes con la misión de establecer el número de habitantes que correspondiera a cada una de las parroquias logroñesas. Las cifras no incluyen a los barrios dependientes de la ciudad, pero son significativas del crecimiento acelerado de Logroño desde que terminó la guerra, pues los sacerdotes censan a 7.545 habitantes en el casco urbano, 500 más que en 1818 y 1.000 más que en 1811. a pesar de que este crecimiento significa una tasa anual de $1,1 \%$, creo que el número de habitantes reflejado corresponde a la realidad demográfica de la ciudad, pues el impulso natalista detectado en 1818 continúa hasta bien entrada la década siguiente, mientras que la mortalidad no presenta ninguna elevación considerable hasta 1828 , y se observa nuevamente un tímido proceso de inmigración hacia Logroño de aquellas zonas que más habían sufrido durante la guerra.

43. ALONSO CASTROVIEJO, J.J, op. cit., pp. 49.

44. GOMEZ URDAÑEZ, J.L, Cenicero Histórico. Logroño 1987 p. 360 y J. L. PASTOR, Transformaciones económicas en Murillo de Río Leza. Tesis de licenciatura inédita. 1986, pp. $71-72$.

45. J.J. AlONSO CASTROVIEJO, «Crisis del Municipio logroñés. Primeros procesos desamortizadores». Brocar número 13. Diciembre, 1987.

46. A.P. Santiago, sin identificación. 


\section{II.E. DICCIONARIOS ESTADISTICOS}

La utilización de las cifras ofrecidas por las recopilaciones eruditas de la primera mitad del siglo XIX ha obviado muchas veces su crítica, dando por ciertas sus informaciones. Sin embargo, un estudio riguroso sobre fuentes originales suele desmentir el material demográfico que presentan estos diccionarios ${ }^{47}$. La ciudad de Logroño no es una excepción y los datos aportados por Miñano ${ }^{48}$ y Govantes $^{49}$ no ofrecen ninguna garantía. El primero de ellos habla de 2.180 vecinos y 8.210 almas, sin especificar la fuente de donde ha obtenido esas cifras, mientras que el segundo cita el censo de la nueva provincia de Logroño realizado en 1821 y que otorga a la ciudad y sus barrios 2.080 vecinos y 8.987 habitantes. La similitud de la cifra de vecinos me hace pensar que ambos utilizaron el mismo vecindario a pesar del error de uno de ellos, motivado quizás por una confusión en la transcripción.

La evidente inflación del censo de 1821 puede deberse a una actitud premeditada de las autoridades logroñesas que intentaban conseguir para la ciudad la capitalidad de la nueva provincia, lo que finalmente consiguieron ${ }^{50}$.

En conclusión, ninguna de las dos cifras puede ser tomada en consideración, pues sobreevalúan la población de Logroño en 1821, como se ha comprobado gracias al plan de demarcación de 1822, que ofrece mayores garantías de verosimilitud.

\section{II.F. CENSO DE POBLACION DE 1836}

El 15 de enero de 1836 aparecía publicada en el Boletín Oficial de la Provincia una circular en la que se exhortaba a los Ayuntamientos a completar un nuevo censo de población con el mayor rigor posible. Las medidas coercitivas que se iban a emplear para asegurar la limpieza del recuento y evitar ocultaciones se centraban en las multas que debían satisfacer los comisionados que realizaran el censo. También se contemplaba el nombramiento de un fiscal especial no avecindado en el lugar al que debía acudir supervisar la operación; otros detalles técnicos completaban la circular ${ }^{51}$.

Diez días después era firmado el censo de la ciudad de Logroño y sus barrios. Logroño contaba con 4.392 habitantes y los barrios de El Cortijo y Varea con 481, en total 4.873 personas, cifra asombrosamente baja. El mismo escribano admitía al final del Censo «que no se ha considerado como vecinos a los empleados de la Real Hacienda, dependientes del resguardo, militares en activo servicio, emigrados y demás personas de accidental residencia de que abunda esta capital con motivo de las actuales circunstancias de la guerra en las provincias confinantes».

Entre 1823 y y 1836 el saldo vegetativo de la ciudad es positivo en 81 personas, a pesar de la crisis de mortalidad infantil del año 1828 y del cólera que azotó Logroño en $1834^{52}$. La epidemia de cólera, unida a la situación de guerra debió empujar a muchas

47. E. FERNANDEZ DE PINEDO, Crecimiento.., p. 88.

48. S. MIÑANO, Diccionario Geográfico Estadistico de España y Portugal. Madrid, 1826, tomo V, p. 243. 108.

49. C. GOVANTES, Diccionario Geográfico Histórico de España. Madrid, 1846, sec. II, p.

50. A.M.Lo. L. A., sesión del 18-X-1821.

51. B.O. Logroño 15-I-1836. El censo en A.M.Lo. I.C.Exp. caja 417.

52. Alonso CASTROVIEJO, J.J., La crisis del Antiguo Régimen... pp. 63-75 


\section{J.J. ALONSO CASTROVIEJO}

familias a salir de Logroño, aunque, como el mismo escribano anota, también fueron muchos los que llegaron huyendo de zonas aún más conflictivas. Por eso, y aun admitiendo que la población descendiera ligeramente, no podemos aceptar una pérdida de 3.153 habitantes sólo en la ciudad en 13 años, por lo que deben ser totalmente rechazadas las cifras ofrecidas por este censo.

\section{II.G. PADRON GENERAL DE LA PROVINCIA DE 1846}

Pascual Madoz apuntaba en su Diccionario ${ }^{53}$ que según la matrícula catastral de 1842 habitaban Logroño 1.588 vecinos que representaban 6.842 almas. Estas cifras están claramente subevaluadas, pues en el Padrón general de la Provincia de Logroño, realizado por orden gubernativa cuatro años más tarde, Logroño capital aparece con 8.699 habitantes -2.008 vecinos-. La mayor crítica que se le debe hacer a este último recuento es que sólo recoge escuetamente la cifra, sin ninguna puntualización sobre la manera en la que ha sido conseguida ${ }^{54}$. Poblaciones como Murillo ${ }^{55}$ o Cenicero ${ }^{56}$, presentan graves discrepancias entre su población real y la que ofrece el Padrón, por lo que creo que es mejor que no sea considerada la población que nos ofrece, pues aunque los indicadores demográficos no presentan graves distorsiones ${ }^{57}$ y pueden ser aceptados sin dificultad es mejor terminar este estudio con el censo de 1857 que sí ofrece todas las garantías de exactitud que se deben exigir a un recuento.

\section{I.H. CENSO DE 1857}

El censo de Logroño y sus barrios de El Cortijo y Varea se realizó por real decreto de 14 de Marzo de $1857^{58}$. La metodología empleada no difiere de la utilizada para los censos de 1787 y 1818 y E. Fernández de Pinedo considera su exactitud similar a la que ofrece el Censo de Floridablanca ${ }^{59}$.

Logroño y sus barrios contaban con una población de derecho de 10.711 habitantes, mientras que los transeúntes eran 528 , que no van a ser considerados, pues en ningún otro recuento estudiado se ha contabilizado la población no avecindada. Estas cifras pueden ser aceptadas sin dificultad, pues hay abundantes testimonios que respaldan ese incremento poblacional ${ }^{60}$.

53. P. MADOZ, Diccionario geográfico-estadístico-histórico de España y sus posesiones de ultramar. Ed. Facsímil, Logroño, 1984, p. 142.

54. B.O. Logroño 3-V-1846.

55. Ibídem.

56. GOMEZ URDAÑEZ, J.L., Cenicero... p. 486. español.

57. La tasa de natalidad, nupcialidad y mortalidad se ajusta a las ofrecidas para el conjunto

58. Preámbulo al Censo de 1857. A.M.Lo. sin siglar.

59. F. GOMEZ, Logroño histórico. Logroño, 1896, p. 324 y E. FERNANDEZ DE PINEDO, Crecimiento... p. 89.

60. Sobre el crecimiento urbano, Concepción CERRILLO, me ha facilitado información sobre la ampliación del casco urbano en zonas de extrarradio para albergar a la masa jornalera. 
Los motivos de un crecimiento absoluto de 3.166 personas en 39 años hay que buscarlos sobre todo en el factor inmigración, ya que Logroño se convirtió en un importante centro de absorción de mano de obra tanto para la realización de obras públicas como el ferrocarril como para la ampliación del casco urbano, que desde la asunción de la capitalidad de la provincia creada en 1834 no había dejado de crecer.

El movimiento natural de la población apenas influyó en el crecimiento de la ciudad, pues el período 1818-1857 fue una etapa de profundas crisis demográficas. Dos epidemias de cólera -1834 y 1854-55- unos años de sobremortalidad -1835-1840- y dos crisis de mortalidad infantil -1828 y los años 1847-1851- impidieron que el saldo vegetativo fuera más favorable, pues se redujo, en estos 39 años a 708 personas, lo que significó un saldo anual de 18 personas, mientras que los aportes inmigratorios se cifraron, sólo para el casco urbano en 60 personas anuales.

\section{II.1. CRECIMIENTO DEMOGRAFICO. 1787-1857}

El estancamiento de población que sufrió Logroño entre 1770 y 1787 se vio tímidamente superado entre 1787 y 1802 . En estos quince años la población creció a un ritmo anual de un $0,38 \%$. La causa principal fue que durante los años 1795-1802 se produjo una coyuntura favorable que permitió que el saldo vegetativo fuera muy positivo. Las cosechas experimentaron una estabilización que ahuyentó el miedo al hambre, pues algunas superficies antes dedicadas al viñedo fueron reutilizadas para la obtención de cereales. Por último también hay que señalar el factor expansivo subsiguiente a todo período bélico y que en Logroño se centró en un considerable aumento de los contratos nupciales.

Esta tendencia alcista se vio frenada drásticamente por la crisis de 1803-1804 y por la Guerra de la Independencia. En 1811 Logroño había perdido un 8\% de sus habitantes, a un ritmo de un $-0,93$ anual, situándose con similar población a la de 1770 .

Con la terminación de la Guerra la ciudad comienza a crecer en su número de hombres. Unos altos índices de nupcialidad en los años 1815-1817 incidieron favorablemente en la natalidad que también incrementó considerablemente sus tasas. Junto a este crecimiento natural, factores políticos coadyuvaron a que Logroño siguiera atrayendo inmigración a pesar de que el viñedo ya no fuera el motor del desarrollo económico de la ciudad. La capitalidad de la provincia, provisional en 1821 y definitiva en 1834, empujó a vecinos de otras zonas de la provincia a residir a Logroño. Los poderosos, porque era la sede del poder; los pobres, porque el crecimiento de la ciudad y la realización de importantes obras públicas demandaban mano de obra abundante. El servicio doméstico también ocupó a una numerosa porción de estos nuevos vecinos.

El ritmo del crecimiento anual entre $1818-1857$ es de un 0,90\%, superior al que se dio en el otro gran momento expansivo del período estudiado, el que va de 1751 a 1770 .

Resumiendo, en la evolución de la población de Logroño entre 1714 y 1857 se pueden establecer estas fases, (vid. gráfico):

1. FASE DE CRECIMIENTO. 1714-1770. Se observa un vigoroso impulso demo-. gráfico motivado por la orientación vinícola de la ciudad. La tasa anual de crecimiento es de un $0,58 \%$, con un subperíodo de desarrollo más dinámico, pues entre 1751 y 1770 la tasa anual es de un $0,81 \%$. 


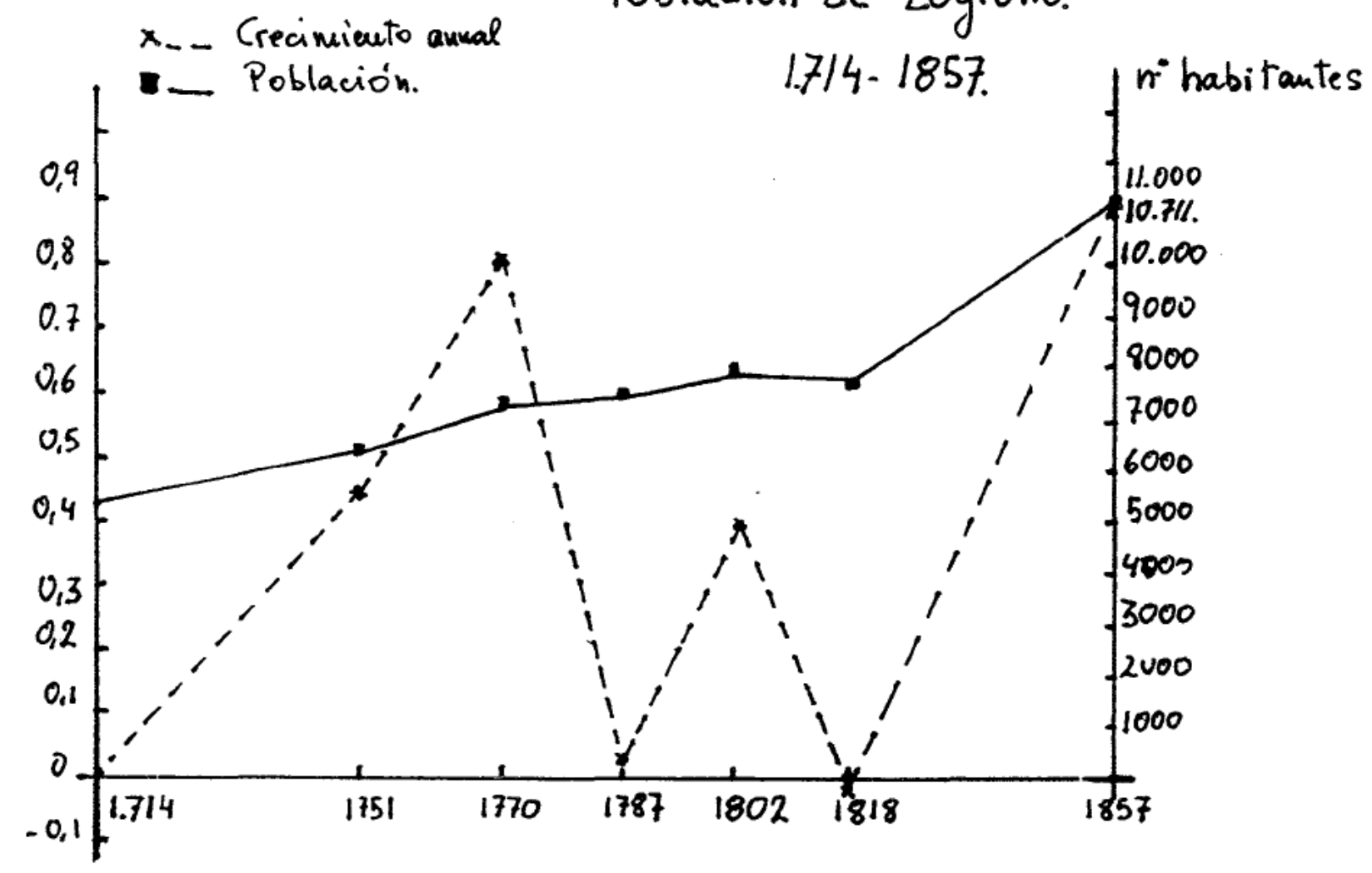

Población de Logroño.

2. FASE DE ESTANCAMIENTO. 1770-1787. Diversas crisis demográficas, unidas a malas cosechas y a una contracción del mercado vinícola impidieron que continuara la tendencia de crecimiento. Entre 1770 y 1787 la tasa anual es de un $0,018 \%$, muy cercana al crecimiento cero.

3. FASE DE CRECIMIENTO. 1787-1802. Entre ambas fechas se produjo una tímida alza demográfica motivada por una coyuntura favorable que duró de 1795 a 1802 . La tasa anual de crecimiento es de un $0,38 \%$ debida exclusivamente a un saldo vegetativo positivo, pues en este período se produce una ligera emigración.

4. FASE DE RETROCESO. 1802-1818. Este intervalo reúne dos subperíodos claramente diferenciados. El primero de ellos fue de pérdidas demográficas, debidas a la crisis de 1804 y a la Guerra de la Independencia. Entre 1802 y 1811 Logroño perdió población a un ritmo anual de un $-0,93 \%$. Por el contrario, entre esta última fecha y 1818 se produjo una importante recuperación demográfica, que permitió volver a los niveles poblacionales de 1802 . Entre las fechas marco el ritmo de crecimiento anual vuelve a ser casi igual a cero, un $-0,04 \%$. 
5. FASE DE CRECIMIENTO. 1818-1857. A pesar de las sucesivas crisis de mortalidad, Logroño experimentó entre estas dos fechas el mayor crecimiento demográfico de todo el período estudiado. Esta fase de crecimiento acelerado tuvo su base en la más fuerte corriente inmigratoria que recibió la ciudad en los cien años acotados. Logroño ejerció una fuerte atracción en un entorno que se estaba pauperizando a marchas forzadas (Cameros, zonas medias de los valles del Najerilla y el Oja...) y que eligieron a la ciudad como lugar de residencia en espera de una emigración de mayor alcance.

\section{CUADRO 6 \\ VECINDARIOS DE LOGROÑO}

BARRIOS
(CORTIJO Y VAREA)

TOTALES

\begin{tabular}{|c|c|c|c|c|c|c|}
\hline AÑOS & VEC. & HAB. & VEC. & HAB. & VEC. & HAB. \\
\hline 1714 & & & & & $(1.294)$ & $(5.176)^{*}$ \\
\hline 1737 & & & & & $(937)$ & $(3.772)^{*}$ \\
\hline 1751 & 1.537 & 5.869 & 75 & 267 & 1.614 & 6.136 \\
\hline 1768 & & $(7.048)$ & & $(360)$ & & $(7.408)$ \\
\hline 1770 & 1.650 & 6.772 & 94 & 386 & 1.744 & 7.158 \\
\hline 1775 & $1.591,5$ & $6.366^{*}$ & & & & \\
\hline 1787 & & 6.790 & & $(390)$ & & $(7.180)$ \\
\hline 1802 & 1.790 & 7.160 & 110 & 440 & 1.900 & $7.600^{*}$ \\
\hline 1811 & $1.645,5$ & 6.582 & 100,5 & 402 & 1.746 & $6.984^{*}$ \\
\hline 1818 & 1.764 & 7.077 & 124 & 467 & 1.888 & 7.544 \\
\hline 1822 & 1.821 & 7.545 & & & & \\
\hline 1846 & & & & & 2.008 & 8.699 \\
\hline 1857 & & & & & (1) & 10.711 \\
\hline
\end{tabular}

* Conversión de vecinos en habitantes utilizando un coeficiente 4.

() Cifras aproximadas, con valor exclusivamente orientativo.

(1) Población de derecho. La población total censada es de 11.239 habitantes. 
